REVISTA CHILENA DE LITERATURA

Abril 2009, Número 74, 139 - 167

\title{
MEDIACIONES DEL YO Y MONSTRUOSIDAD: SOR JUANA O EL "FÉNIX” BARROCO ${ }^{1}$
}

\author{
David Solodkow \\ Universidad de los Andes \\ dsolodko@uniandes.edu.co
}

RESUMEN / ABSTRACT

El siguiente artículo explora uno de los textos más importantes del barroco novohispano titulado "Respuesta a Sor Filotea" (1691) escrito por Sor Juana Inés de la Cruz (1648?-1695). El objetivo del artículo es analizar los modos de constitución de la subjetividad (criolla y femenina) en la Nueva España y las transacciones discursivas y retóricas utilizadas a tal fin. El artículo también examina las relaciones entre poder, saber y deseo dentro de la ciudad letrada y los dispositivos discursivos de control y resistencia a dicho poder colonial y religioso. El análisis pone de manifiesto la existencia de una subjetividad heterogénea, fragmentaria y en perpetua negociación y tensión con los discursos sociales de la época.

PALABRAS ClaVe: subjetividad, discurso, retórica, agencia, poder.

The following article explores one of the most important texts of New Spain's Baroque titled "Respuesta a Sor Filotea", written by Sor Juan Inés de la Cruz. The main objective of the article is to analyze the ways in which female and Creole subjectivity are constructed in New Spain. At the same time, the article explores the discursive and rhetoric transactions involved in the construction of that subjectivity. The article also examines the relationships between power, knowledge and desire within the de colonial lettered city, and the discursive devices of control and resistance to colonial and religious power. The analysis of the text shows the existence of an heterogeneous and fragmentary subjectivity in constant negotiation and tension with the social discourses of that time.

KEY WORDS: subjectivity, discourse, rhetoric, agency, power.

1 Quiero agradecer las muy útiles e inteligentes sugerencias a este escrito realizadas por el profesor Benigno Trigo de la Universidad de Vanderbilt (Nashville, USA). 
El escrito de Sor Juana (Juana Ramírez de Asbaje [1648?-1695]) conocido bajo el título de Respuesta a Sor Filotea (Marzo de 1691) es un texto central en las letras de Hispanoamérica por múltiples razones. En primer lugar, porque se trata de una defensa de las letras profanas en medio de un ambiente religioso y cerrado. En segundo lugar, porque es un texto que mantiene viva una de las primeras voces de la Nueva España que se alzó para preguntar quiénes y por qué razón tenían el derecho a conocer, leer, pensar y escribir. Finalmente, porque en la escritura de este texto se trazan las huellas de una construcción subjetiva y singular que nos posibilita analizar y conocer en detalle la inestabilidad de los dispositivos discursivos de control social en la ciudad letrada novohispana y, simultáneamente, atestiguar la emergencia de una nueva conciencia femenina y criolla. Prestigiosos críticos literarios como Octavio Paz (1982), Marié-Cécile Benassy-Berling (1983), Josefina Ludmer (1985), Jean Franco (1989), Margo Glantz (1992, 1995), Georgina Sabat de Rivers (1998), Martínez-San Miguel (1999), Luciani (2004), entre otros, han mostrado con insistencia y rigor analítico la extraordinaria riqueza que la Respuesta exhibe no solo en su arquitectura retórico-lingüística, sino también en el ámbito de las dimensiones políticas, filosóficas, religiosas y culturales que el texto articula en el interior del entramado material y simbólico de la sociedad colonial novohispana.

En este artículo me propongo revisar la Respuesta a Sor Filotea con el objetivo múltiple de analizar la configuración discursiva del sujeto enunciador, esto es, las técnicas de la máquina retórica barroca que se ponen en juego dentro la Respuesta y las potencialidades e imposibilidades que dicha máquina plantea para la representación de la subjetividad. Al mismo tiempo, me interesa examinar las relaciones discursivas del texto con su entorno cultural e institucional, las configuraciones de poder entre el yo que habla y un "otro" que escucha: las torsiones propias de un sujeto que responde amenazado a través de un movimiento de articulación paradójica, de la sinuosidad de la letra, de un espacio de fragmentación, mediación y ambigüedad lingüística, construcciones que se forman mediante la elusión y la mascarada nominal (travestismo lingüístico). Finalmente, me propongo repensar la función social de un sujeto colonial heterogéneo, desgarrado y "monstruoso" en el espesor del murmullo de la ciudad letrada novohispana. 


\section{SOR JUANA NO FUE UN SUBALTERNO COLONIAL}

El subalterno colonial -el indígena, el esclavo africano- no puede hablar o expresarse en el ámbito letrado colonial. Quizás sea mejor decir que el subalterno colonial habla allí donde su voz es silenciada o interpretada por el letrado ${ }^{2}$. En esa piedra muda de su alteridad abyecta, tanto el mundo cultural como los deseos y pensamientos del subalterno son interpretados y traducidos. Sin embargo, la traducción de la voz del subalterno no es la voz del subalterno. Se trata, mejor, de una ilusión, de una representación o mediación que no capta sino un posible remedo de la abyección en la que ese subalterno habita, siempre dominado por la escritura del poder. El caso de Juana Ramírez de Asbaje (1648-1695) es "radicalmente" diferente al de los múltiples subalternos coloniales. La monja jerónima discurre ante los sabios ${ }^{3}$, habla por intermedio de su escritura, conversa en el locutorio con su amigo Carlos de Sigüenza y Góngora (1645-1700) sobre tratados científicos y sobre poesía, sus loas son representadas, sus villancicos cantados en las iglesias, sus obras son publicadas en vida ${ }^{4}$. Si hay una acción a través de la cual se puede definir su existencia -a diferencia de la del subalterno concreto de la ciudad letrada colonial- ella sería, justamente, la de no parar de decir. Si acaso se

2 A propósito de las posibilidades de hablar o no del subalterno, Gayatri Chakravorty Spivak señala que: "If in the context of Colonial production, the subaltern has no history and cannot speak, the subaltern as female is even more deeply in shadow" ("Can the Subaltern Speak?" 83).

3 Margo Glantz, citando a Diego Calleja, reconstruye la escena del interrogatorio por el cual pasó la joven monja: "Como el mismo Calleja lo afirma con 'certitud no disputable', cuando relata la muy célebre escena en que Juana Inés contesta, ante la corte, ese "gran teatro del mundo", las preguntas que 40 sabios le hacen para comprobar si su "sabiduría tan admirable”, era "infusa” o "adquirida”, esto es sobrenatural o humana” (¿Hagiografia o autobiografia? 16).

4 El primer tomo de la obras de Sor Juana se publicó en Madrid en 1689 bajo el pomposo título de Inundación Castálida de la única poetisa, Musa Décima, Sor Juana Inés de la Cruz, religiosa profesa en el Monasterio de San Jerónimo de la Imperial Ciudad de México, que en varios metros, idiomas y estilos, fertiliza varios asuntos, con elegantes, con sutiles, claros, ingeniosos, útiles versos; para enseñanza, recreo y admiración, dedícales a la Excma. Señora Doña María Luisa Gonzaga Manrique de Lara, Condesa de Paredes, Marquesa de la Laguna, y los saca a la luz Don Juan Camacho Gayna Caballero del Orden de Santiago, Mayordomo y Caballerizo que fue de su Excelencia, Gobernador actual de la Ciudad del puerto de Santa María. Pero hubo, como señala Margo Glantz, incluso una segunda edición de 1690 (¿Hagiografia o autobiografia? 15). 
dijera que el silencio no es parámetro suficiente para definir la subalternidad de un sujeto, y que es necesario, además, incluir dentro del marco conceptual del subalterno nociones tales como las de género, raza y clase, aun así, sería muy difícil definir al sujeto discursivo que no para de hablar a través de la investidura lingüística textual de, por ejemplo, La Respuesta a Sor Filotea, o del Primero sueño, como a un sujeto de tipo subalterno. Como afirmaba Alfonso Méndez Plancarte, la incomparable notoriedad de Sor Juana como personaje público de la época es ya una evidencia irrefutable que se constata en el hecho de que:

\begin{abstract}
Sus rimas se canten en eventos cortesanos o familiares de los virreyes; que el Cabildo Metropolitano le encargue su Arco Triunfal para los marqueses de la Laguna; que las catedrales de México, Puebla y Oaxaca le pidan villancicos a 'su erudición sin segunda y siempre acertado entendimiento': que el obispo de la Angelópolis le bautice y le imprima su Carta Atenagórica, y que los dos primeros tomos de sus obras -reimpresos ya en su vida- la exalten como la 'Única Poetisa Americana, Musa Décima' (76).
\end{abstract}

En tal sentido, Sor Juana no fue un subalterno y tampoco fue la portavoz de una heterodoxia que combatía en forma subversiva el status quo y, probablemente, ni siquiera se la puede considerar -si es que tal movimiento anacrónico de sobreimposición retórica sobre la episteme discursiva colonial es viable- como la "primera feminista de América". Sin embargo, ello no significa que en el análisis de la subjetividad multiposicional que se enuncia a través de sus obras no pueda leerse una defensa del derecho al conocimiento por parte de las mujeres, fundamentalmente, la defensa del conocimiento individual, del derecho de sí misma ${ }^{6}$. En la escritura de Sor Juana vemos una

5 Tal es el título de uno de los acápites en la "introducción” a la edición de la Respuesta realizada por el Grupo Feminista de Cultura (1979). Sin embargo, el propio autor colectivo que firma este prólogo, esto es, el Grupo Feminista de Cultura, trata sutilmente de atemperar el impetuoso título de primera feminista de América argumentando que: "Si por feminista entendemos a una mujer que ha tomado conciencia de su opresión como mujer y trata de influir de algún modo para transformar esta realidad, podemos decir que Juana es feminista, en la medida en que podía serlo una mujer sola, en la segunda mitad del siglo XVII" ("Introducción" 19).

6 La Respuesta trata principalmente de la defensa del conocimiento individual, del derecho de Sor Juana a aprender y no de una promoción colectiva para todas las mujeres; no extraigo 
cierta agencialidad restringida a las mecánicas disciplinarias del poder, a ese espacio complementario y extrínseco al discurso (las reglas institucionales), y a las posibilidades retóricas de enunciación colonial, de su complejo entramado epistemológico, de sus formaciones discursivas y de sus reglas de enunciación históricas ${ }^{7}$.

Si detenemos la mirada con cierta atención detallista en el comienzo mismo de la Respuesta, es posible leer la pregunta ontológica que guía el impulso de la estructura profunda de este texto a lo largo de sus páginas: “¿Por ventura soy más que una pobre monja, la más mínima criatura del mundo y la más indigna de ocupar vuestra atención?" $(26)^{8}$. Independientemente de que dicha afirmación deba entenderse dentro del marco retórico de la falsa modestia, esa interrogación abierta presupone una visualización y un emplazamiento del sujeto enunciador: una colocación dentro de una estructura de poder que solo es posible a partir de un movimiento de aparente humildad, bajo el cual la voz de la narración se presenta ${ }^{9}$. Como señala Ludmer: "Este es también un lugar, un locus retórico denominado 'modestia afectada'; no nos interesa como tal sino en la medida en que magnifica al otro y lo marca con un exceso que produce no saber decir" (49). Este incipit de la carta, entonces, se

esta idea de una inferencia personal, Sor Juana misma lo afirma: "leer públicamente en las cátedras y predicar en los púlpitos, no es lícito a las mujeres; pero que el estudiar, escribir y enseñar privadamente, no solo les es lícito, pero muy provechoso y útil; claro está que esto no se debe entender con todas, sino con aquellas a quienes hubiere Dios dotado de especial virtud y prudencia y que fueren muy provectas y eruditas y tuvieran el talento y requisitos necesario para tan sagrado empleo" (Respuesta 56, énfasis mío).

7 Las reglas de formación son herramientas teóricas de análisis del discurso que tomo en préstamo del método arqueológico que propone Michel Foucault. De acuerdo con Foucault: "se llamarán reglas de formación las condiciones a que están sometidos los elementos de esa repartición [el sistema de dispersión de los enunciados] (objetos, modalidad de enunciación, conceptos, elecciones temáticas). Las reglas de formación son condiciones de existencia (pero también de coexistencia, de conservación, de modificación y de desaparición) en una repartición discursiva determinada" (Archaeology 62-64).

8 En adelante todas las citas de la Respuesta son tomadas de la edición del Grupo Feminista de Cultura (1979).

9 Asunción Lavrin señala con relación al tópico de la humildad que: "The adulation of the most notable men of her time, and of the members of the viceregal court, could hardly have kindled a sense of humility in her. Rhetorical disclaimers of her own worthlessness aside, she was well aware of her intellectual capacity, and only under great duress did she suffer orders from her own superiors to suppress her writings or change their character" (Feminist Perpectives 70). 
corresponde con una colocación subjetiva que fijará, a partir de la falsedad de su modestia, un sinuoso movimiento de recolocaciones subjetivas múltiples y de mediaciones lingüísticas frente al verticalismo del poder a través del juego retórico que mayormente se define a partir de la paradoja ${ }^{10}$.

Presentar al yo, hacer presente al ser, inscribir(se) como sujeto del discurso abre entonces una cadena ontológica de referencialización: defensa de un ente que para marcar su subjetividad en el curso de la historia narrativa debe nombrarse, afirmándose en un proceso de rememoración genealógica. Ese movimiento implica un proceso de singularización, esto es: objetivarse como sujeto de la acusación y parapetarse como agente de la defensa para abrirse camino en la diversidad anónima y múltiple de la circulación social del discurso ${ }^{11}$. Al mismo tiempo, el proceso de singularización implica una

10 De acuerdo con Ludmer, la Respuesta contiene por lo menos tres textos: 1) lo que escribe directamente al Obispo, 2) lo que se ha leído como su biografía intelectual y 3) la polémica sobre la sentencia de Pablo "callen las mujeres en la iglesia". El silencio constituye su espacio de resistencia ante el poder de los otros: "Hay así tres instancias superiores que ordenan la relación con los tres elementos mencionados: la madre, el Obispo y el Santo Oficio, que imponen temor y generan no decir; no decir que se sabe (a la madre), decir que no se sabe (al Obispo), y no decir por no saber (en el campo de la teología)" (50). Para Ludmer, Sor Juana erige una cadena de negaciones: no decir, decir que no sabe: "Este doble gesto combina la aceptación de su lugar subalterno (callar como mujer), y su treta; no decir pero saber, o decir que no sabe y saber, o decir lo contrario de lo que sabe. Esta treta del débil, que aquí separa el campo del decir (la ley del otro) del campo del saber (mi ley) combina, como todas las tácticas de resistencia, sumisión y aceptación del lugar asignado por el otro, con antagonismo y enfrentamiento" (51-52).

11 Siguiendo la descripción de los eventos históricos realizada por Octavio Paz (534-50), la polémica dentro de la cual se enmarca la Respuesta puede ser sintetizada como sigue: en noviembre de 1690 apareció en la ciudad de Puebla un folleto que llevaba por título: Carta Atenagórica de la madre Juana Inés de la Cruz. Atenagórica. El escrito de Sor Juana, en forma de carta, es una crítica a un sermón del jesuita portugués Antonio de Vieyra. Se trata de una argumentación de tema teológico en la cual se discute cuál fue, en vida, la mayor fineza de Cristo. Vieyra sostenía que Cristo no quiso la correspondencia de su amor para sí, sino para los hombres, y que esta fue su mayor fineza; amar sin correspondencia. Sor Juana, por el contrario, aunque en su poesía haya afirmado la idea de Vieyra y no la suya, cree lo contrario, que Cristo sí pide correspondencia para su amor. La publicación de la Carta Atenagórica, realizada sin la expresa voluntad de Sor Juana, venía precedida de un prólogo en el que una persona encubierta bajo el título de Sor Filotea, si bien elogiaba el entendimiento de Sor Juana, la conminaba a dedicarse a otras cosas. Sor Filotea era, nada más y nada menos, que el confesor de Sor Juana, el Obispo de Puebla, Manuel Fernández de Santa Cruz. Como señala Paz, la publicación de la carta produjo un daño irreversible para Sor Juana, la cual fue, a partir 
cierta conexión con aquello que la crítica literaria denomina género autobiográfico.

De acuerdo con Sylvia Molloy, no es posible pensar en la autobiografía como género consolidado en el campo de las letras de América Latina sino hasta el siglo XIX. Por ello, decir que la Respuesta es una autobiografía sería, de algún modo, violentar el texto de Sor Juana o, en todo caso, someterlo a una imposición genérica anacrónica. Sin embargo, debido a la presencia de cierto tono autorreflexivo, Molloy señala que: "La Respuesta de Sor Juana Inés de la Cruz al obispo de Puebla o las confesiones ante el tribunal de la Inquisición podrían considerarse -y de hecho se han considerado- autobiografías. Sin negar la preocupación por el yo que aparece en esos textos, propongo que su finalidad primaria no es autobiográfica, aun cuando la autobiografía constituya uno de sus logros involuntarios" (13; énfasis mío). Uno de los problemas de esta cita de Molloy quizás sea el oscuro significado de conceptos tales como "finalidad primaria" y "logros involuntarios". Claro que se entiende que el objetivo de Molloy es señalar cierta conciencia autoral al momento de escribir, esto es: afirmar que Sor Juana en realidad escribe presionada por circunstancias políticas y que no quiere escribir una autobiografía. La escritura de la poetisa estaría enmarcada, por lo tanto, no en la producción de una escritura sobre sí misma, sino en la necesidad de articular una defensa, en responder. No obstante, en el caso de Sor Juana, el movimiento retórico de la defensa de sí implica una tautología, esto es, que hay un yo que defender ${ }^{12}$.

La escritura de la Respuesta envuelve un movimiento que, lejos de responder a la construcción de una unidad subjetiva homogénea, se relaciona más bien con una duplicación o, mejor, con una diseminación: un sujeto empírico

de allí, atacada desde todos los ángulos imaginados. Juana Inés no tardó mucho tiempo en contestar al prólogo de la Carta Atenagórica, y ese documento es el que conocemos como la Respuesta a Sor Filotea (538).

12 Para una detallada comprensión del estilo retórico de la carta es indispensable leer el artículo de Koldobika Josu Bijuesca titulado "Una mujer introducida a teóloga y escriturista: exégesis y predicación en la Respuesta" en Sor Juana \& Vieira: trescientos años después (1998). En dicho artículo se señala que: "la Respuesta responde de lleno a las convenciones del género retórico judicial o forense en su variante de defensa, en algunas partes también pueden detectarse otros elementos heterogéneos, procedentes de las técnicas para la predicación y la interpretación de las Escrituras, que sirven a la utilitas de la causa que Sor Juana trata de defender y que, en última instancia, también tienen su origen en la retórica clásica” (95). 
(Sor Juana) debe defender a un sujeto gramatical ${ }^{13}$. El sujeto empírico que escribe y el yo gramatical que referencializa al primero intentarán hacerse coincidir en el espacio de la escritura. Una aparente tautología montada sobre la ilusión de intercambiabilidad de los términos Yo / Sor Juana. Pero las dificultades no se agotan allí, ¿cuál de los dos términos es anterior y fundante? ¿Cuál conlleva la posibilidad de sustento del otro? ¿Es el yo lingüístico que atraviesa la Respuesta una clara y directa referencia al sujeto Sor Juana al cual estaría fundando y, de este modo, una exterioridad con la cual se corresponde? O por el contrario ¿existe un sujeto empírico soberano anterior a la escritura que se da sentido a sí mismo pero que paradójicamente no puede ser sino a través de su representación y a la mediación lingüística del yo que aparentemente "la dice" en la escritura? ${ }^{14}$

Defenderse a sí misma en el caso de Sor Juana implica, por lo tanto, construirse como sujeto del discurso en el discurso, como objeto de la defensa, esto es: representar(se), contar(se), decir(se), inventar(se), comparar(se), menospreciar(se), acordarse de sí, mentir(se), predicar sobre el yo. Por ello, no existe una agencia previa a la Respuesta; dicha agencialidad se construye discursivamente y esto adquiere sentido si recordamos que el ámbito de circulación de la Respuesta es, nada más y nada menos, que aquel de la ciudad letrada. El yo debe ser dicho en una situación de defensa, bajo un ataque en el que el propio sujeto discursivo, gramatical y figurado debe escamotearse retóricamente, plegarse en la paradoja y, al mismo tiempo, decir(se) para defenderse. Es por ello que el análisis textual de la escritura novohispana de finales del siglo XVII se ofrece como un espacio privilegiado para reflexionar

13 Yolanda Martínez-San Miguel es una de las críticas que ha llamado la atención acerca de las múltiples posiciones subjetivas que encarna Sor Juana en tanto que sujeto colonial novohispano. Al respecto afirma que: "Sor Juana representa en sus obras toda una serie de sujetos coloniales que se integran a una discursividad que ya se puede empezar a llamar criolla" (Saberes americanos 13).

14 En tal sentido, Paul de Man sugería una reversibilidad con relación al análisis tradicional en la construcción de lo autobiográfico, según el cual: "We assume that life produces the autobiography as an act produces its consequences, but can we not suggest, with equal justice, that the autobiographical project may itself produce and determine the life and that whatever the writer does is in fact governed by the technical demands of self-portraiture and thus determined, in all its aspects, by the resources of his medium? And since the mimesis here assumed to be operative is one mode of figuration among others, does the referent determine the figure, or is it the other way round" (920). 
sobre los dispositivos epistemológicos y retóricos en pugna hacia el interior de la conflictiva sociedad colonial, y permite entender, fundamentalmente, un doble movimiento en la superficie textual: aquél que se refiere a las determinaciones institucionales y otro en donde se estaría operando una resistencia subjetiva contradiscursiva -aunque ni contrahegemónica ni contracolonial en el caso de Sor Juana- de ese mismo poder: la creación de un relato de identidad.

\section{PROCESOS DE SINGULARIZACIÓN Y ENMASCARAMIENTO}

Cualquiera que sea la metodología empleada [...] salta a la vista la enorme (y a veces hasta malsana) curiosidad que el personaje despierta: en los varones porque fue mujer; en la mujeres, porque es posible convertirla en una de las primeras feministas y erigirla como modelo; en los críticos católicos porque, por añadidura fue monja; en los poetas y críticos literarios porque, siendo una extraordinaria poeta, fue además una gran intelectual y científica; y los intelectuales la injertan -por su actividad filosófica y su capacidad de trasgresión-a sus propia teorías sobre el mundo.

Glantz, Margo ¿Hagiografia o autobiografia?

Sor Juana habla de un "especial modo de avergonzarme y confundirme: que es más primoroso medio de castigar hacer que yo misma, con mi conocimiento, sea el juez que me sentencie y condene mi ingratitud" (27; énfasis mío). La lógica de esta frase se sustenta en una negación que está presente desde el inicio en la Respuesta, negación a imponerse un (auto)castigo o una (auto)condena frente a la acusación de Sor Filotea:

Si el crimen está en la Carta Atenagórica, ¿fue aquélla más que referir sencillamente mi sentir con todas las venias que debo a nuestra Santa Iglesia? Pues si ella, con su santísima autoridad, no me lo prohíbe, ¿por qué me lo han de prohibir otros? [...] Mi entendimiento tal cual, ¿no es tan libre como el suyo, pues viene de un solar? [...] Demás que yo ni falté al decoro que a tanto varón se debe [Vieyra] [...] ni escribí más que para el juicio de quien lo insinuó. [...] Pues como yo fui libre para disentir de Vieyra, lo será cualquiera para disentir de mi dictamen (64). 
Esa condena debería ser la de callar y por ello es posible afirmar que, entre otras cosas, la Respuesta es un paradójico y complejo tratado sobre el silencio y sus significaciones. Sor Juana presenta lo que considera sus "digresiones" iniciales como excusas (efugios) que intentan "huir la dificultad de responder" (27). Esta dificultad no es menor puesto que estuvo a punto, dice Sor Juana, de conducirla "al silencio" (27). Y el silencio en sí mismo, dice la monja, es "negativo" (27), y por ello hay que "ponerle algún breve rótulo para que se entienda lo que se pretende que el silencio diga" (27). Ahora bien, el silencio "dice", sin embargo, Sor Juana no calla y en cambio nos propone una posibilidad con respecto al callar, al silencio: su interpretación. No es casual que la Respuesta, si acordamos en pensarla como un tratado sobre el silencio, tenga como su tema central -si bien no exclusivo ni excluyente- la frase del Apóstol san Pablo (Corintios I, XIV, 34): "Mulieres in Ecclesiis Taceant, nom enim permititur eis loqui" [Cállense la mujeres en la iglesia, porque no les es dado hablar]. Frase apostólica sobre la cual Sor Juana impondrá una modificación genérica: "Y en verdad no lo dijo el Apóstol a las mujeres, sino a los hombres; y que no es solo para ellas el taceant, sino para todos los que no fueren muy aptos" (57). De acuerdo con Sor Juana, el callar no implica no tener nada que decir, sino: "no caber en las voces lo mucho que hay que decir" (28). La consecuencia lógica que se deriva de ello es que si la monja no calla es porque tiene algo que decir y lo que tiene para decir sí cabe en su voz. Estas elucubraciones primeras se estructuran entonces sobre la matriz paradójica de su discurso: "solo responderé diciendo que no sé que responder" (28). Curioso que a esta afirmación sobre un supuesto "no saber" le sigan cuarenta y cinco páginas de escritura, es más, que incluso a esta respuesta Sor Juana la autocalifique permanentemente como escrita por su propia "ignorancia": “ Oh si todos -y yo la primera, que soy una ignorante- nos tomásemos la medida al talento antes de estudiar [...] qué poco ánimo nos quedara y de cuántos errores nos excusáramos [...] Y pongo las mías en primer lugar, pues si conociera, como debo, esto mismo no escribiera [la Respuesta] Y protesto que solo lo hago por obedeceros"! (58).

La utilización de la máscara nominal será uno de los recursos a partir de los cuales Sor Juana callará, tomando rostros prestados: se trata del travestismo simbólico del que nos habla Paz. Este procedimiento debe ser entendido dentro del marco de la relación de poder sobre el cual se encuadra la Respuesta. En dicho marco, la posición subjetiva sorjuanesca debe mostrarse por debajo de la autoridad que solicita la respuesta. Este enmascaramiento se realizará, fundamentalmente, a través del símil bíblico que desde el principio 
es utilizado en el texto con un doble propósito: por un lado, el gesto de tomar máscaras prestadas encubriendo el enunciado personal con la sentencia sagrada y, por otro, el de poner en evidencia el conocimiento de la monja sobre temas teológicos. El primer movimiento de enmascaramiento a través del símil bíblico es aquél que se refiere a la figura de Moisés. Sor Juana presenta su supuesto "no saber" qué responder a partir de la imagen balbuceante del Moisés niño: "No se hallaba digno Moisés, por balbuceante, para hablar con Faraón, y, después, el verse tan favorecido de Dios, le infunde tales alientos, que no solo habla con el mismo Dios, sino que se atreve a pedirle imposibles: Ostende mihi faciem tuam" (28). Este es el coraje de Moisés que sirve a Sor Juana como identificación del suyo propio: una forma indirecta de decirle al travestido cura a quien responde (Fernández de Santa Cruz) que él también exponga la cara, que se muestre, que deje caer su máscara. Aquí el yo enmascarado como Moisés, le dice al $t u$ (Filotea), colocándolo en la posición que a su autoridad le corresponde, que diga quién es y por qué la obliga a defenderse. La intención, entonces, es desenmascarar el travestismo de Filotea mediante el enmascaramiento propio a través de la figura de Moisés, repitiendo el proceso figurativo paralelo del cura (masculino) que se hace pasar por una monja (femenino) e invirtiendo el proceso: la monja (femenino) se inviste retóricamente de Moisés (masculino) ${ }^{15}$. Solo así, sabiendo que es viable la equiparación retórica a partir de un enmascaramiento, será posible comenzar a discutir. Se trata de una batalla nominal-figurativa por desenmascarar el rostro ajeno mediante una estrategia retórica de hablar a través de las palabras de un otro (Moisés). Un juego de mostrar (el rostro ajeno) ocultando, simultáneamente, el rostro propio.

Una vez que el procedimiento ha mostrado su potencialidad para equipararse en el juego con el Otro enmascarado, Sor Juana, negando el movimiento que la acaba de equiparar, se somete nuevamente al poder al que se dirige:

15 Como ha señalado Jean Franco, este juego ya había sido practicado por Sor Juana en el Primero sueño con el objetivo de lograr una neutralidad autoral: "Each of these different positions of enunciation constitutes a move within a particular set of rules and frequently it is a destabilizing move - either because the enunciating and gendered voice mimics the conventions to the point of parody, or because it takes gender differentiation out of the rules of the game, thus untying the apparently natural association of the male with power [...] The fictionalization of the 'I' and the system of representation that worked through allegorical 'characters' were a necessary mask" (29). 
"Y así, debajo del supuesto de que hablo con el salvoconducto de vuestros favores y debajo del seguro de vuestra benignidad, y de que me habéis [...] dado a besar la punta del cetro de oro de vuestro cariño en señal de concederme benévola licencia para hablar" (29). Esto es, habla porque supone que Filotea se lo permite, de otro modo no hablaría. Esta afirmación es usada para mostrar a su interlocutor que está consciente de la situación en la que escribe: una suerte de reaseguro verbal de que no se va a exceder, de que va a cumplir, de que se va a retractar. Sin embargo, pronto nos encontramos con un nuevo desequilibrio en la aparente postura sumisa de Sor Juana. La monja insiste en que no escribió más sobre las Sagradas Letras -lo cual constituye una de las acusaciones de Filotea- puesto que para tales menesteres ella se conoce "tan incapaz y para cuyo manejo soy tan indigna" (29). Además de tener que presentarse con modestia, como veíamos al principio, y de reconocer que habla porque el cetro de oro le ha "dado licencia", Sor Juana debe ejecutar un largo procedimiento de denigración personal: no ser digna de, no ser capaz de, no ser inteligente, no tener nada que decir. Sin embargo es a partir de este menosprecio de sí que la voz narrativa propondrá una inversión radical mostrando, en primer lugar, y como señal de un mayor gesto de irreverencia que: a) sí sabe sobre Sagradas Letras, b) que sí tiene argumentos para responder, c) que sí es capaz de razonar bajo el modelo silogístico y que por ende, d) sí es inteligente. Apenas cinco renglones más abajo de la afirmación de su supuesto desconocimiento sobre las Sagradas Letras, Sor Juana habla de la prohibición histórica que se hacía a los hombres con relación a la lectura del Cantar de los cantares y sobre la "oscuridad" que entraña el libro del Génesis. Movimiento de conocimiento afirmativo sobre dos aspectos clave de la hermenéutica bíblica que borra y niega su aparente "no saber" afirmado previamente.

A medida que avanza la escritura la voz narrativa parece ir borrando del texto las marcas de aquellas afirmaciones que está obligada a realizar en el marco de aparente sumisión que debe representar ante el poder de su interlocutor. Se trata del movimiento en espiral del que nos habla Paz en el cual "cada avance es un regreso" (550). Una escritura que progresa gracias al impulso supresor de lo que va afirmando. El texto niega a sí mismo su capacidad para enunciarse como verdad y muestra su maleabilidad silogística; un procedimiento en el que la interpretación es una síntesis entre la afirmación constante de un "no saber" y simultáneamente su negación. Estructura flexible que le permite al sujeto de la enunciación inscribirse como entidad oblicua al afirmar que "no sabe" mediante su saber. Esta cadena referencial ontológica, 
solo posible en la estructura dialéctica de la paradoja, es doblemente útil como instrumento de defensa: en primer lugar, el yo acusado que hay que defender es y no es, o es huella en la grieta, un puro escamoteo y, en segundo lugar, este movimiento constante, este salto ontológico repetitivo abre el juego simultáneo del mostrar como enmascaramiento, como ilusión imposible de recuperar al yo detrás de la afirmación que se va negando. La enunciación del texto parece decir "estoy aquí, en el lugar en el que acabo de desaparecer". Debe existir, entonces, un elemento de viabilidad epistemológica y discursiva que le permita a esta subjetividad en construcción deconstructiva inscribir la huella multiposicional de su ontología en repliegue. A mi modo de ver, el inestable entrecruzamiento de saberes parciales en Sor Juana (como reflejo de una inestabilidad cultural periférica novohispana) es lo que le permite este juego retórico paradójico: el (des)orden simbólico del lenguaje colonial ${ }^{16}$. La teratología ontológica sorjuanesca se configura a partir de este juego discursivo barroco en permanente tensión, articulado a partir de aquello que se nos muestra, ocultándose constantemente. En ello radica el proceso de singularización sorjuanesco como aberratio: una identidad que se refleja en la pura distopía de su ser no siendo y de su no ser siendo, en el confuso y contradictorio entramado epistemológico novohispano.

La consagración de su monstruosidad en tanto que sujeto múltiple, en tanto que inversión de roles genéricos (travestismo simbólico), en tanto que su agudo conocimiento de la literatura peninsular y de temas (proto)científicos, la alcanza Sor Juana en la Respuesta. No obstante, es necesario remarcar que este largo proceso de singularización tiene comienzo muy temprano en la vida de la monja. La curiosidad de la que nos habla Margo Glantz en el epígrafe que abre este acápite es parte de una herencia cuya genealogía se remonta a la época misma en la que vivió Sor Juana. En tal sentido, es posible entender esa subjetividad multiforme, heterogénea y multiposicional

16 De acuerdo con Frederick Luciani, uno puede encontrar en la escritura de Sor Juana: "[T]races in her self-fashioning of negotiations among a number of authoritative institutional discourses. The most important of the latter are those of the Catholic Church and the viceregal court, each marked by internal discrepancies and contradictions, and sometimes openly antagonistic each toward the other. Other cultural practices that shaped Sor Juana's self-fashioning would include the dual patronage systems of court and Church, the ephemeral nature of viceregal administrations, conduits and barriers of literary production, publication and trade between Spain and her American colonies, social organization and control in New Spain based on caste, class, and gender" (17; énfasis míos). 
a la cual nominamos como Sor Juana, precisamente, como a un largo proceso de singularización y mediación discursiva, mecanismo de circularidad monstruosa de la ciudad letrada en la que se mueve desde los catorce años, un proceso del cual la monja tratará de separarse infructuosamente. Dicho proceso de atribución teratológica devela los esfuerzos interpretativos de clérigos, cortesanos y hombres de letras -de los quebraderos de cabeza de la elite cultural novohispana- por tratar de comprender la monstruosidad sorjuanesca, su caso, su rareza, su extraordinaria capacidad intelectual y su erudita formación libresca. Como afirma Glantz:

Convertida en Fénix, está en la cima de la monstruosidad. Bien lo entiende ella así, sabe que es mirada como si fuera un bufón, un objeto de circo, el centro de atracción. Se le ha otorgado un lugar especial entre las mujeres, se la ha etiquetado, separado, y el disturbio que su genial inteligencia y su excepcional discreción han provocado puede mantenerse bajo control: se le ha dado un nombre. Sin embargo, la atención que se le presta puede asemejarse, repito, a la que reciben los fenómenos en las ferias o los bufones en la corte [...] Su sabiduría provoca 'espanto' (¿Hagiografia o Autobiografía? 31-33; énfasis míos).

Tenemos así un "Fénix", un "bufón”, un "objeto de circo", un "centro de atracción”, un “fenómeno de feria”. Esta atribución teratológica probablemente sea aquello que conduce la escritura de la Respuesta hacia el gesto de inscripción autobiográfico. Una necesidad de justificación pública de su monstruosidad, mediante la revisión (a modo de confesión) de su propia genealogía. En tal sentido, la propia monja afirma que escribir "nunca ha sido dictamen propio" (31) y que "nunca he escrito sino violentada y forzada y solo por dar gusto a otros; no solo sin complacencia, sino con positiva repugnancia" (31). Curiosa afirmación si tenemos en cuenta el caudal significativo de su obra. Sin embargo, le es imposible negar que: “[...] desde que me rayó la primera luz de la razón, fue tan vehemente y poderosa la inclinación a las letras, que ni ajenas reprensiones -que he tenido muchas-, ni propias reflejas -que he hecho no pocas-, han bastado a que deje de seguir, este natural impulso que Dios puso en mí" (31). Este discurso providencialista y fatalista excusa a la monja de tener que justificarse en términos personales: ella no puede parar de escribir puesto que se trata de algo congénito, de una atribución que la divinidad ha puesto en ella. Nueva paradoja, si la intención es separarse de su propia monstruosidad, si lo que intenta es mostrar la naturalidad de un 
acto (escribir), en la explicación que ella misma da no hace sino mostrarse como una señalada de Dios, esto es, como alguien que ha sido marcada por, tocada por y comisionada por la divinidad.

Es preciso recordar aquí la etimología de la palabra monstruo como aquello que se muestra, como una señal que da aviso ${ }^{17}$. Es más, lo monstruoso en la narración de sí misma se asocia a la idea de prodigio, haciendo que desde el comienzo de su propia vida se presente como una niña diferente, precoz: "no había cumplido los tres años de mi edad cuando enviando mi madre a una hermana mía [...] a que se enseñase a leer [...] me llevó tras ella el cariño y la travesura; y viendo que le daban lección, me encendí yo de manera en el deseo de saber leer, que engañando, a mi parecer, a la maestra, le dije que mi madre ordenaba que diese lección [...] y supe leer en tan breve tiempo, que ya sabía cuando lo supo mi madre" (32-33). Este párrafo es muy significativo puesto que en él aparecen ciertos autobiografemas clave: en primer lugar, la constitución del momento, del instante, en el que la pasión o el deseo se revelan a la niña objetivándose en una actividad (leer); por otra parte, el deseo y la "travesura" - en tanto que mentir a la madre y engañar a la maestra- que desestabilizan, como actos conscientes de la voluntad deseante, la afirmación providencial sobre la "inclinación natural". Continúa Sor Juana: "Acuérdome que en estos tiempos, siendo mi golosina la que es ordinaria en aquella edad, me abstenía de comer queso, porque oí decir que hacía rudos, y podía conmigo más el deseo de saber que el de comer" (33). Una subjetividad que se (auto)inflige castigos con el objetivo de acceder al conocimiento. Es posible leer en este trazo genealógico infantil una cierta resonancia narrativa del génesis, del pecado adánico, de la tentación alimenticia. Doble efecto, es una vuelta sesgada y sutil a la afirmación de su conocimiento sobre el libro sagrado, pero al mismo tiempo, una muestra del potencial imaginario-literario de las letras sagradas para la constitución subjetiva y autorreferencial de los sujetos de la época. En este sentido, es

17 Michael Palencia Roth en su brillante artículo sobre la teratología de la Conquista, nos informa que: "Según Aristóteles, 'la primera característica del monstruo es la de ser diferente [anomoíon en griego] (La generación de los animales IV, iv 770b, 5-6), y presentar una especie de 'deformidad' [anatería en griego] (IV, iv, 769b, 30) [...] Generalmente, el monstruo - tera en griego, monstrum en latín - se parece al ser humano y al mismo tiempo se diferencia de él. El término tanto en griego como en latín (tera o monstrum) tiene connotaciones religiosas, sea en relación con los dioses paganos o con el dios cristiano" (40). 
necesario remarcar la alta productividad discursiva de la analogía no solo con personajes bíblicos como modelos morales -incluso el mismo Cristo-, sino también con personajes que informan la historia universal del catolicismo y, en mayor medida, con santas, pero también con diosas de la mitología clásica griega y romana, musas y pitonisas, todas: "insignes mujeres [...] y otras infinitas, en otras especies de prendas y virtudes" $(54)^{18}$.

Sor Juana, tratando de separarse de las redes teratológicas que la han encasillado desde su pubertad, intentando mostrar su inclinación y deseo como cosas "naturales" y no monstruosas, sin embargo, nos presentará una niña prodigio que aprende a leer en meses, que escribe desde los nueve años y que discute con los sabios a edad de catorce. En cierto sentido, como lo han señalado Electa Arenal y Amanda Powell en su "Introducción” a la traducción inglesa de la Respuesta, Sor Juana estaba, de algún modo, negociando su propia monstruosidad y haciendo uso medido de ella para beneficio propio como una treta más de su supuesta debilidad. Ello sugiere que Sor Juana, al intercambiar sentidos, al negociar su identidad, entra en una relación económica con la epistemología barroca y su potencia desfiguradora ${ }^{19}$. La característica de la cornucopia barroca, su hiperbolización constante del lenguaje, la utilización de retruécanos lingüísticos y de juegos de ingenio impiden cualquier tipo de naturalización, justamente, porque aquello que está en juego es un modelo silogístico rebuscado, hecho de finezas, basado en la constante artificialidad de sus efectos retóricos. Por ello, romper la monstruosidad atribuida mediante el juego paradójico que ofrece su Respuesta -borrarse en la afirmación, negar el ser para ser, travestirse asumiendo rostros

18 Entre otras, cita a Catalina de Alejandría, Débora, la Reina de Saba, Abigail, Ester, Rahab, Ana, Minerva, Atenea, la hija de Tiresias, Cenobia, Arete, Nicostrata, Aspasia Milesia, Hispasia, Leoncia, Jucia, Corina, Cornelia, Paula, Blesila, Eustaquio, Fabiola, Proba Falconia, La reina Isabel de Castilla, Alejandra, Marcela, Pacátula, Leta, Gertrudis, Brígida, Marta, María, Salomé, Agreda, Santa Teresa, y agrega Sor Juana: "y en fin a toda la gran turba de las que merecieron nombres, ya de griegas, ya de musas, ya de pitonisas; pues todas no fueron más que mujeres doctas, tenidas y celebradas y también veneradas de la antigüedad por tales" (54).

19 Al respecto, Arenal y Powell indican que: "Respect for exceptionality was in part a reflection of the profound seventeenth century interest in unusual natural phenomena that viewed artistic talent and intellectual drive in females as fascinating abnormalities. Sor Juana learned to exploit the fact that she was catalogued as a prodigy; she both defended and derided the hyperbolic terms of price her exceptionality attracted" (2). 
masculinos- imposibilita que Sor Juana pueda desprenderse de su propia monstruosidad: el lenguaje devora a la monja en la acumulación de los símiles y múltiples rostros, en la multiposicionalidad nominal que asume para decir, en la fragmentación. Inscribirse como "identidad" supone un juego peligroso en las trampas del lenguaje; trampas que al permitir la emergencia de la subjetividad, al mismo tiempo la borran y la dispersan. En tal sentido, llama la atención del lector moderno esa capacidad del lenguaje sorjuanesco de denunciar su propia artificialidad, la monstruosidad tropológica a la que nos somete el lenguaje y la insistencia en señalar la des-figuración subjetiva que acontece en cada predicado sobre el yo. Existe en Sor Juana una conciencia lingüística que por ser tal permite la irrupción de una subjetividad acomodaticia. Esta característica barroca hace posible la recolocación permanente de la subjetividad novohispana y la negociación ontológica en el entramado de la autoridad discursiva y jerárquico-institucional de la época. Se trata de la proto-formación de las agencias criollas, de sus gérmenes epistémicos que, como tan lúcidamente ha señalado José Antonio Mazzotti, se sustentan en la "ambigüedad colonial" y cuyo carácter "dialógico e interactivo", será la base para la configuración de subjetividades "ontológicamente inestables" (Introducción 20) ${ }^{20}$.

A medida que avanza la Respuesta, Sor Juana sigue apuntalando las particularidades de su monstruosidad: "de manera que cuando vine a México, se admiraban, no tanto del ingenio, cuanto de la memoria y noticias que tenía en edad que parecía que apenas había tenido tiempo para aprender a hablar" (33). Aquí se nos muestra una suerte de yo en espejo, un yo que se mira en el presente de la enunciación como sorprendida de sí. Pero la aparente naturalidad de sus dotes es inmediatamente contrastada por lo que Sor Juana señala como una conciencia de autodisciplina, un cuidado de sí, que incluso la separa y diferencia de los rasgos superficiales que caracterizan a las otras mujeres:

[...] y era tan intenso mi cuidado, que siendo así que en las mujeres

-y más en tan florida juventud- es tan apreciable el adorno natural

20 Mazzotti, siguiendo a Smith propone que el término agencia resulta: "más flexible y dinámico que la de sujeto puesto que "the human agent exceeds the subject as it is constructed in and by much postestructuralist theory as well as by those discourses against which postestructuralist theory claims to pose itself"' (15). 
del cabello, yo me cortaba de él cuatro o seis dedos midiendo hasta donde llegaba antes, e imponiéndome ley de que si cuando volviese crecer hasta allí no sabía tal o cual cosa que me había propuesto deprender en tanto que crecía, me lo había de volver a cortar en pena de la rudeza: que no me parecía razón que estuviese vestida de cabellos cabeza que estaba tan desnuda de noticias (34).

Es mediante la inserción del autobiografema que la voz narrativa busca un movimiento de diferenciación con el resto -en este caso mujeres-, como si su defensa se basara en la posibilidad de ser absuelta, como en un caso de demencia jurídica, a partir del reconocimiento de su singularidad por parte de la autoridad. El monstruo -como dispositivo cultural, como imagen representacional de la alteridad y la diferencia-, al menos desde la epopeya de Gilgamesh, pasando por el cíclope de la Odisea homérica, es un ser solitario que vive recluido y alejado de la sociedad, ya porque la sociedad le teme, ya porque él teme a la sociedad. En tal sentido, reconociendo su particular "inclinación" monstruosa, su diferencia con el resto de las mujeres que solo se preocupan por el cabello, Sor Juana elige la reclusión como modo de apartarse, ya de su incomprensión de los hábitos sociales como el matrimonio, ya para poder abrazar la soledad y dedicarse a lo único que le interesa, sus libros:

Entréme religiosa, porque aunque conocía que tenía el estado de cosas (de las accesorias hablo, no de las formales), muchas repugnantes a mi genio, con todo, para la total negación que tenía al matrimonio, era lo menos desproporcionado y lo más decente que podía elegir en materia de la seguridad que deseaba de mi salvación; a cuyo primer respeto (como al fin más importante) cedieron y sujetaron la cerviz todas las impertinentillas de mi genio, que eran de querer vivir sola; de no querer tener ocupación obligatoria que embarazase la libertad de mi estudio, ni rumor de comunidad que impidiese el sosegado silencio de mis libros (34).

De este modo es posible entender cómo en el proceso de narración de sí misma, en el gesto especular que utiliza para decirse, Sor Juana nos devuelve una imagen que muestra la diferenciación con el resto, una imagen sustentada en la clausura (recogimiento) y en la singularización, con el aislamiento como solución y la autodisciplina como metodología. Un "monstruo ordenado", recluido, deseante de su propia salvación que, no obstante, producirá uno de los mayores ruidos en el interior de la ciudad letrada novohispana. El problema para la elite intelectual novohispana era cómo explicar el sentido 
de ese "ruido social" producido por el monstruo. El Fénix conventual recluido, a través de la escritura, seguirá llamando la atención del circo barroco: "Cierto, señora mía, que algunas veces me pongo a considerar que el que se señala -o le señala Dios, que es quien solo lo puede hacer-es recibido como enemigo común, porque parece a algunos que usurpa los aplausos que ellos merecen o que hace estanque de las admiraciones a que aspiraban, y así le persiguen" (43). Sor Juana muestra, de este modo, que los acontecimientos en los que ha resultado su vida son menos los de una voluntad personal que los del deseo y la avidez del círculo letrado por el incentivo de su propia monstruosidad; incentivo que, paradójicamente, deviene en celos y envidia de esa comunidad que la festeja.

\section{PODER, SABER Y DESEO EN EL MODELO AUTODIDÁCTICO SORJUANESCO}

El "monstruo", por momentos congénito y natural, por momentos voluntario, que nos presenta el yo narrativo, debe ser interpretado en el marco de las negociaciones de poder dentro de la estructura institucional novohispana. En tal sentido, sería erróneo creer que la mascarada sorjuanesca se basa en un principio de esquizofrenia balbuceante; tal concepción de la escritura sorjuanesca le quita al acto retórico su potencia y su agencialidad en tanto que defensa de sí. Sin embargo, es notorio que Sor Juana, implicada en una pulsión deseante por (auto)defenderse, explicar(se) y, por momentos, justificar su propia monstruosidad, incurra en ciertas contradicciones inconscientes que claramente no puede manejar. Creo necesario señalar el doblez como multiposicionalidad agentiva, pero también como manifestación inconsciente producto de un sujeto que es, al mismo tiempo, objeto e instrumento de las redes de saber/poder.

En ciertos momentos de la Respuesta, es posible notar una lucidez sufriente que se asoma a la superficie textual. Quizás la misma se deba a esa trampa doble del aparato ideológico novohispano que manipula las subjetividades en la pragmática necesidad de objetivación y orden, al mismo tiempo que las somete a la esquizofrenia del exceso incontenible que sus propias redes de saber no pueden normalizar. Se trata de esa obsesión epistémica novohispana por contener la diferencia, normalizar las subjetividades, aplacar la ansiedad cultural que propone la otredad y, finalmente, encontrar un analogon que pueda subsumir la monstruosidad bajo el signo de lo idéntico. En esos 
momentos de la Respuesta en donde vemos asomarse cierta ansiedad por la explicabilidad del yo, la potencia retórica parecería estar denunciando una condena que pesa sobre ese yo, una suerte de presión inevitable contra la cual Sor Juana lucha infructuosamente por desprenderse: su propia monstruosidad, las "impertinencillas de mi genio" (34).

La atmósfera religiosa con la que cuenta Sor Juana para pensar el exceso de su propio ser, su aberratio en tanto que niña prodigio, no puede sino pensarse dentro del marco católico-institucional para tales casos: el pecado y la tentación. Dos ejes que imponen al exceso, al sobrante monstruoso, otro exceso igualmente significativo, la culpa. ¿Por qué si la "inclinación” es "natural”, si la gente le pide que siga siendo el monstruo que anima las cortes, le es requerido, al mismo tiempo, que confiese su monstruosidad, que la declare, que abomine de ella e, incluso, que la sienta como culpa? En tal sentido, el convento debería ser el lugar de resguardo necesario, el continente de la monstruosidad, la línea demarcatoria dentro de cuya territorialidad cerrada el monstruo es normalizado a partir de la repetición de tareas cotidianas que Sor Juana siente como insoportables. Sin embargo, Sor Juana es muy consciente de que la monstruosidad habita en ella y por eso afirma que: "Pensé yo que huía de mí misma, pero ¡miserable de mí!, trájeme a mí conmigo y traje mi mayor enemigo en esta inclinación, que no sé determinar si por prenda o castigo me dio el Cielo, pues de apagarse o embarazarse con tanto ejercicio que la religión tiene, reventaba como pólvora, y se verificaba en mí el privatio est causa appetitus" (35). La privación y la clausura, tienden a generar un efecto contrario al deseado, incentivan el apetito. Foucault ha mostrado la existencia de una estrecha relación de complementariedad entre la reclusión y la escritura que desde el Imperio romano ha sentado una larga tradición en occidente: la escritura vendría a paliar los peligros que entraña la soledad y a ofrecer una mirada sobre los propios pensamientos del que escribe. La escritura se ofrece, de este modo, como una compañía. Es por ello que la escritura como una práctica de ascesis ofrece una extraordinaria posibilidad para controlar y conocer los impulsos internos del alma; la misma se configura como el dispositivo que puede traer a la luz los impulsos más profundos del pensamiento y dispersar la oscuridad espiritual en donde los malos pensamientos habitan (Foucault, "Self Writing" 207-208).

Hay algo incontrolable que se denuncia en la Respuesta, un exceso cuya potencia no se puede controlar o normalizar, una tensión que flota en el aire del propio convento, algo que incentiva el appetitus y que obliga a los obispos a escribir una serie interminable de reglamentos, manuales de conducta y 
tratados que intentarán poner orden en la tensión, disipar el exceso y castigar su emergencia. El exceso producido por el/los objeto(s) de deseo -conocer, leer y escribir- se inscribe con una potencia puramente afirmativa en la Respuesta. Ese deseo es la muestra palpable de la incontinencia de la monja, su desborde erótico, una pulsión libidinal sublimada en el objeto libro: "Volví (mal dije, pues nunca cesé); proseguí, digo, a la estudiosa tarea (que para mí era descanso en todos los ratos que sobraban a mi obligación) de leer y más leer, de estudiar y más estudiar, sin más maestro que los mismos libros" (35). Una doble impugnación al encierro que supuestamente debería corregir el desvío de todo exceso. Por una parte, no cesa de leer y por otra parte reclama y afirma un (auto)didactismo que desafía la autoridad institucional en sus bases jerárquicas. Sin embargo, no trata Sor Juana de hacer una revolución institucional. Probablemente conoce sus propios límites en relación con un cambio sustancial del sistema educativo para las mujeres y, por ello, como bien ha señalado Marié-Cécile Benassy-Berling, el sistema educativo por el que aboga es uno de: “enseñanza 'privada', la poetisa no reclama verdaderas universidades femeninas, enuncia principios generales, y no hace alusión a una cualquiera reforma del régimen que vivían las niñitas en los conventos de México y de otros lugares. En un primer tiempo, por lo menos, la jerónima piensa visiblemente en 'grupos' con efectivos reducidos o clases dedicadas a una sola alumna" (275).

De este modo, la Respuesta informa al lector cómo el "monstruo" recluido y por su cuenta se dedicó al estudio de lógica, física, retórica, música, aritmética, geometría, arquitectura e historia. En este punto de la Respuesta, Sor Juana hace un despliegue positivo de su conocimiento, de las cosas que aprendió leyendo, sola y recluida. Estos conocimientos generales sobre tantos tópicos y materias, este exceso de conocimiento redunda, según Sor Juana, en el hecho de que: "he estudiado muchas cosas y nada sé, porque las unas han embarazado a las otras" (38). Sin embargo, ello no implica una falsa modestia sino una queja, a saber: "porque como es menester mucho uso corporal para adquirir hábito, nunca le puede tener perfecto quien se reparte en varios ejercicios" (39). Esto es, como ha tenido que dedicarse a menesteres que son propios de la vida conventual y por tener negado como mujer su ingreso a la universidad, no ha tenido la posibilidad de formarse sistemáticamente como un intelectual de academia. Ahora bien, la defensa de su conocimiento se basa, precisamente, en la negación de la necesidad de prácticas sistemáticas de estudio y en la afirmación de las virtudes del autodidactismo. La multiplicidad de saberes superpuestos, de disciplinas 
mezcladas que ha adquirido, si bien se presentan como prácticas un tanto desordenadas y desprolijas, muestran, sin embargo, su positividad y valor en el campo de la especulación: "[los saberes que ha adquirido] muestran lo contrario, y quisiera yo persuadir a todos con mi experiencia a que no solo no estorban [el conjunto heterogéneo de disciplinas], pero se ayudan dando luz unas para las otras, por variaciones y ocultos engarces [...] de manera que parece se corresponden y están unidas con admirable trabazón y concierto" (39). Es posible apreciar el modo en que el yo narrativo le da sentido a una red heterogénea de saberes con un propósito muy definido: mostrar que sí conoce, que su conocimiento es singular por los modos particulares en los que ha tenido que adquirirlos -en un convento sin maestros-, y cómo esos conocimientos, gracias a la labor intelectiva, cobran eficacia en el marco de la reflexión especulativa. Esta afirmación desafía por sí sola todo orden jerárquico-institucional, puesto que propone la viabilidad de un individuo que no necesita de las redes institucionales para su apuntalamiento intelectual: "Yo de mí puedo asegurar que lo que no entiendo en un autor de una facultad, lo suelo entender en otro de otra que parece muy distante; y esos propios, al explicarse, abren ejemplos metafóricos de otras artes: como cuando dicen los lógicos que el medio se ha con los términos como se ha una medida con dos cuerpos distantes, para conferir si son iguales o no" (39). Este proceder intelectivo de Sor Juana ayuda al lector contemporáneo a comprender los modos particulares de funcionamiento de las redes epistémicas de la ciudad letrada mexicana y además permite comprender los modos en los cuales la subjetividad deseante, el saber y el poder, se interceptan en una pugna constante por definir los métodos de efectividad y plausibilidad para la adquisición del conocimiento de la época.

Foucault ha mostrado no solo las relaciones implícitas entre saber y poder, sino que además ha explicado cómo, en el análisis de la epistemología de los siglos XVI y XVII, la resemblanza -que Sor Juana utiliza constantemente para explicarnos su proceso de aprendizaje- es el modo imperativo a partir del cual se entrecruzan las redes de saber. Un conjunto de operaciones de cotejo, de similitud, de analogías que se remiten las unas a las otras y que se explican en una cadena de identificaciones infinita ${ }^{21}$. Este mismo proceso

21 Según Foucault: "Resemblance played a constructive role in the knowledge of Western culture. It was resemblance that largely guided exegesis and the interpretation of texts; it was 
que permite adquirir conocimiento a partir del cotejo analógico es también el que posibilita la utilización de máscaras discursivas para el yo narrativo. $\mathrm{Su}$ fama, aquella por la cual ha sido aclamada por la corte, es al mismo tiempo la causa de la envidia general. Utilizando nuevamente el proceso del símil bíblico, Sor Juana explica que no otra distinta fue la causa de la persecución de Cristo: los fariseos lo perseguían por su "divina hermosura" (43). A Cristo lo envidiaban por su hermosura, a ella, por sus conocimientos y capacidades: " $i$ Oh signo que te ponen por blanco de la envidia y por objeto de la contradicción! Cualquiera eminencia, ya sea de dignidad, ya de nobleza, ya de riqueza, ya de hermosura, ya de ciencia, padece esta pensión; pero la que con más rigor la experimenta es la del entendimiento[...] Cabeza que es erario de sabiduría no espere otra corona que de espinas" (45-46). Se trata de una larga disquisición sobre la persecución de Cristo y los motivos de sus adversarios que Sor Juana utiliza para comparar su caso: "En todo lo dicho, venerable señora, no quiero (ni tal destino cupiera en mí) decir que me han perseguido por saber, sino solo, porque he tenido amor a la sabiduría y a las letras, no porque haya conseguido ni uno ni otro" (49). La similitud que está utilizando Sor Juana se monta en un juego de peligroso equilibrio: es una mujer, una monja, que está comparando sus virtudes y las causas de su amonestación con los hechos de la vida de Cristo. Una analogía que puede llevarla, eventualmente, a retractarse frente a la inquisición. La cadena analógica se ofrece como una máquina que una vez encendida no puede parar su funcionamiento. Como afirmo más arriba, esta cadena de analogías comienza con la figura de Moisés, se continúa con la de Cristo y se prolonga hasta el Príncipe de los apóstoles, Pedro. De la figura del mismo Pedro se sirve Sor Juana para mostrar las penurias por la que debe atravesar todo santo: "era afecto a la sabiduría, llevábale el corazón, andábase tras ella, preciábase de seguidor y amoroso de la sabiduría [...] Ni faltó soldado de afuera que no le afligiese, ni mujer doméstica que no le aquejase" (49). Este amor por el conocimiento la ha conducido a lo que ella misma califica como "tal extremo" (50). Al haber alcanzado ese punto, Sor Juana comenta cómo "se le prohibía el estudio" (50), sin embargo, la cadena analógica -la estructura mental que se mueve a través de las resemblanzas-no puede prohibirse, es un marco conceptual que

resemblance that organized the play of symbols, made possible knowledge of thing visible and invisible, and controlled the art of representing them" (The Order of Things 17). 
está en la conciencia intelectual de la época, un motor que no puede parar y que por causa de ello expone el exceso de su peligrosidad:

[Y] me mandó que no estudiase. Yo la obedecí [...] en cuanto a no tomar libro, que en cuanto no estudiar absolutamente, como no cae debajo de mi potestad, no lo puedo hacer, porque aunque no estudiaba en los libros, estudiaba en todas las cosas que Dios crió, sirviéndome ellas de letras, y de libro toda esta máquina universal. Nada veía sin reflejo; nada oía sin consideración, aun en las cosas más menudas y materiales; porque como no hay criatura, por baja que sea, en que no se conozca el me facit Deus, no hay alguna que no pasme el entendimiento, si se considera como se debe (50).

El mundo es un libro que, mirado atentamente, enseña la obra divina. El mundo como libro, según Ernst Robert Curtius, es un tropo con una larga tradición en las letras de occidente que se puede hallar a lo largo de toda la Edad Media latina $^{22}$. En ese sentido, no es improbable que Sor Juana haya retomado esta idea del teatro de Calderón, o de algunos de los autores que integraban su biblioteca, la cual, según el padre Calleja, constaba de más de cuatro mil volúmenes ${ }^{23}$. De todos modos, lo que me importa remarcar aquí no es tanto la tradición heredada por la Nueva España y Sor Juana en materia de metáforas medievales, como el hecho de que esa metáfora se inscribe en un tipo particular de episteme cuyo funcionamiento se basa en la resemblanza de los elementos de la naturaleza. Como señala Foucault: "In the vast syntax

22 De acuerdo con Curtius: "Uno de los lugares comunes favoritos del concepto popular de la historia consiste en decir que el Renacimiento se sacudió el polvo de los viejos pergaminos a fin de leer en el libro de la naturaleza o del mundo. Pero aún esta misma metáfora proviene de la Edad Media latina" (448). El objetivo de Curtius es mostrar la evolución y productividad de esta metáfora; así, por ejemplo, nos informa que: "En el pensamiento de Paracelso, las metáforas del libro desempeñan un papel fundamental. A los libros escritos - codices scribentium - opone Paracelso el libro 'dado, escrito, dictado y arreglado por Dios mismo'. Los enfermos deben ser el libro del médico. La naturaleza es una suma de libros completos" (451). Finalmente, según Curtius, es Galileo quien toma esta metáfora y revoluciona el campo científico: "El creador de la física exacta habla del gran libro del universo, que está constantemente frente a nuestros ojos, pero que no puede ser leído sino por los que han aprendido su escritura" (455).

23 Informa el padre Calleja: "Nadie la oyó jamás quejosa ni impaciente; su quitapesares era su librería, donde se entraba a consolar con cuatro mil amigos, que tantos eran los libros de que la compuso" (Vida 36). 
of the world, the different beings adjust themselves to one another; the plant communicates with the animal, the earth with the sea [...] There is something in emulation of the reflection and the mirror: it is the means whereby things scattered through the universe can answer one another" (The Order 18-19). De este modo, a partir de la simple observación de la vida cotidiana, Sor Juana extrae conclusiones en la lectura del mundo como libro: "Si veía una figura, estaba combinando la proporción de sus líneas y mediándola con el entendimiento y reduciéndola a otras diferentes" (50), o:

Estaban en mi presencia dos niñas jugando con un trompo, y apenas yo vi el movimiento y la figura, cuando empecé con esta mi locura, a considerar el fácil motor de la forma esférica, y cómo duraba el impulso ya impreso e independiente de su causa, pues distante la mano de la niña, que era la causa motiva, bailaba el trompillo; y no contenta con eso, hice traer harina y cernerla para que, en bailando el tropo encima, se conociese si eran círculos perfectos o no los que describía con su movimiento; y hallé que no eran sino unas líneas espirales que iban perdiendo lo circular cuanto se iba remitiendo el impulso (51).

Todas las cosas en el mundo reflejan el conocimiento, la estructura interna de sus leyes: desde un juguete como el trompo, pasando por las líneas estructurales del techo de su dormitorio e, incluso, la cocción de los alimentos:

¿Qué os pudiera contar, Señora, de los secretos naturales que he descubierto estando guisando? Veo que un huevo se une y fríe en la manteca $o$ aceite y, por contrario, se despedaza en el almíbar; ver que para que el azúcar se conserve fluido basta echarle una muy mínima parte de agua en que haya estado membrillo u otra fruta agria; ver que la yema y clara de un mismo huevo son tan contrarias, que en los unos, que sirven para el azúcar, sirve cada una de por sí y juntos no (52).

El remate formidablemente humorístico de esta reflexión sobre el aprendizaje de la naturaleza, el resumen de este noviciado de lo cotidiano, del mundo como libro, concluye con Sor Juana enviando al filósofo Aristóteles a la cocina: "Si Aristóteles hubiera guisado, mucho más hubiera escrito" (52). Impresionante despliegue de irreverencias: si la privan de los libros -como de hecho sucedió- ella aprende de lo cotidiano, si no le dan maestros y le niegan el aprendizaje, aprende sola, en forma autodidáctica. Lo interesante 
de notar aquí es cómo el mismo sistema epistemológico que estructura el pensamiento de la intelectualidad novohispana, aquella red conceptual que tiene su manto teratológico sobre los sujetos excedidos permite, al mismo tiempo, que los sujetos se apropien de él para acomodarse en la grieta conceptual, en los intersticios que el propio poder no puede saturar. Se trata de los amagos de ese sujeto multiforme de la ciudad letrada novohispana que debe montar una lucha permanente entre su deseo desgarrado y las redes epistémicas del poder colonial.

\section{OBSERVACIONES FINALES}

Esa subjetividad multiforme y heterogénea -en perpetua mediación-a la cual llamamos Sor Juana se desarrolla dentro de un ámbito cultural complejo y de un tiempo histórico bien circunstanciado. Se trata de una plurisubjetividad -en el sentido de que dicha subjetividad está atravesada por diversos órdenes simbólicos- y de una multiposicionalidad -en el sentido de los desplazamientos subjetivos que se realizan mediante las mascaradas nominales, las citas de autoridad y la utilización del símil. Un plurisubjetividad que ocurre en el interior de ciertos sectores particularizados de esa sociedad de anillos concéntricos que describía Ángel Rama y dentro de un orden barroco ligado a la exclusividad de ciertas prácticas lingüísticas asociadas a la morfología institucional de la ciudad letrada: el púlpito, la cátedra, los certámenes poéticos de la corte y la tertulia conventual ${ }^{24}$. Es en ese desorden ordenado barroco que Sor Juana participará haciéndose eco de los límites materiales y simbólicos que ese marco cultural le impone.

He pretendido mostrar con mi análisis los modos específicos de funcionamiento de la maquinaria retórica en uno de los textos más significativos

24 Al respecto Rama señala que: "La ciudad bastión, la ciudad puerto, la ciudad pionera de las fronteras civilizadoras, pero sobre todo la ciudad sede administrativa que fue la que fijó la norma de la ciudad barroca, constituyeron la parte material, visible y sensible, del orden colonizador, dentro de las cuales se encuadraba la vida de comunidad. Pero dentro de ellas siempre hubo otra ciudad, no menos amurallada sino más agresiva y redentorista, que la rigió y condujo. Es la que creo debemos llamar la ciudad letrada, porque su acción se cumplió en el prioritario orden de los signos y porque su implícita calidad sacerdotal, contribuyó a dotarlos de un aspecto sagrado [...] Obviamente se trataba de las funciones culturales de las estructuras de poder" (24-25). 
de la poetisa mexicana con el objetivo de evaluar los modos particulares de constitución subjetiva y mediación en la sociedad novohispana de finales del siglo XVII. El resultado de esta exploración crítica muestra la complejidad de los dispositivos retóricos a partir de los cuales Sor Juana construye los límites problemáticos de los discursos que constituyen su identidad. Una identidad en plena tensión con las redes institucionales del poder. Dispositivos asociados a la mascarada nominal (travestismo) posibilitada por un sistema de analogías y resemblanzas, mecanismos prototípicos de la epistemología de la época. Asimismo, he tratado de demarcar las potencialidades y los límites para la representación subjetiva y la singularización del yo que ofrecen las redes analógicas del pensamiento barroco colonial, examinando las relaciones de poder institucional que se tienden entre el yo que enuncia su defensa y derecho al conocimiento y un Otro inquisidor que escucha. La Respuesta de Sor Juana se hace posible y efectiva únicamente a través de un movimiento de articulación paradójica, mediante determinadas técnicas de elusión, elisión y enmascaramiento nominal, gracias al pliegue y al repliegue de la letra; en otras palabras, de una constante mediación y negociación discursiva de su estatuto identitario. De este modo, el análisis da cuenta de la existencia de un sujeto colonial heterogéneo en el entramado confuso y concéntrico de la ciudad letrada novohispana, al cual le es posible afirmarse identitariamente a través de las torsiones y los juegos lingüísticos de la maquinaria retórica barroca. Se trata de una identidad en permanente fuga, en permanente construcción: una identidad inestable que amenaza el orden simbólico a causa de la monstruosidad que el poder institucional reconoce como puro exceso, desborde que agita las ansiedades culturales poniéndolas en tensión. Un exceso al que hay que controlar, normalizar y, finalmente -como se hizo-, acallar.

\section{BIBLIOGRAFÍA}

Benassy-Berling, Marié-Cécile. Humanismo y religión en Sor Juana Inés de la Cruz. México D.F.: UNAM, 1983.

Calleja, Diego. Vida de Sor Juana. México D.F.: Antigua Librería Robredo, 1936.

Cruz, Juana Inés de la. Respuesta a Sor Filotea de la Cruz. Barcelona: Laertes, 1979.

The Answer / La Respuesta (including a selection of poems). Electa Arenal, Amanda Powel, critical edition and translation. New York: The Feminist P. at the U. of New York, 1994. 
Curtius, Ernst, R. Literatura europea y Edad Media Latina. 2 vols. México, D.F.: FCEM, 1999.

De Man, Paul. “Autobiography as De-facement”. Modern Language Notes 94 (1979): 919930.

Foucault, Michel. The Archaeology of Knowledge. New York: Pantheon Books, 1972.

"Self Writing". Ethics, Subjectivity and Truth. Paul Rabinow, ed. New York: The New Press, 1997.

The Order of Things: An Archaeology of the Human Sciences. New York: Vintage Books, 1994.

Franco, Jean. Plotting Women. New York: Columbia UP, 1989.

Glantz, Margo. Borrones y borradores: reflexiones sobre el ejercicio de la escritura (ensayos de literatura colonial, de Bernal Díaz del Castillo a Sor Juana). Virginia: Ediciones del equilibrista, 1992.

Sor Juana Inés de la Cruz: ¿Hagiografia o Autobiografia? México D.F: Grijalbo, 1995.

Josu K. Bijuesca. "Una mujer introducida a teóloga y escriturista: exégesis y predicación en la Respuesta”. Sor Juana y Vieira: trescientos años después. Ed. Josu K. Bijuesca y Brescia Pablo. Santa Bárbara: Anejo de la revista Tinta, 1998. 95-113.

Larvin, Asunción. "Unlike Sor Juana? The Model Nun in the Religious Lieterature of Colonial Mexico". Feminist Perspectives. Merrim, Stephanie, ed. Detroit: Wayne State UP, 1991. 61-86.

Luciani, Frederick. Literary Self-Fashioning in Sor Juana Inés de la Cruz. Lewisburg: Bucknell UP, 2004.

Ludmer, Josefina. "Tretas del débil". La sartén por el mango. González, Patricia Elena y Ortega, Eliana, eds. Puerto Rico: Huracán, 1985.

Martínez-San Miguel, Yolanda. Saberes americanos: subalternidad y epistemología en los escritos de Sor Juana. Pittsburgh: Series Nuevo Siglo, 1999.

Mazzotti, José Antonio, ed. Agencias Criollas: la ambigüedad 'colonial'en las letras hispanoamericanas. Pittsburgh: Biblioteca de América, 2000.

Méndez Plancarte, Alfonso. Críticas de críticas sorjuanianas. Recopilación e introducción de Octaviano Valdés. Toluca: Instituto Mexiquense de Cultura, 2000.

Merrim, Stephanie, ed. Feminist Perspectives. Detroit: Wayne State UP, 1991.

Molloy, Sylvia. Acto de presencia: la escritura autobiográfica en Hispanoamérica. México D.F.: El Colegio de México y FCEM, 1996.

Palencia-Roth, Michael. "Enemigos de Dios: los monstruos y la teología de la conquista". Heterotropias: narrativas de identidad y alteridad latinoamericana. Carlos Jáuregui y Juan Pablo Dabove, eds. Pittsburgh: Biblioteca de América, 2003. 39-62.

Paz, Octavio. Sor Juana Inés de la Cruz o las trampas de la fe. Barcelona: Seix Barral, 1982.

Rama, Ángel. La ciudad letrada. Hanover: Ediciones del Norte, 1984. 
Sabat de Rivers, Georgina. En busca de Sor Juana. México D.F: Facultad de Filosofía y Letras (UNAM), 1998.

Spivak, Gayatri Chackravorty. “Can the Subaltern Speak?”. Colonial Discourse and PostColonial Theory (A reader). Williams, Patrick, and Chrisman, Laura, eds. New York: Columbia UP, 1994. 